\title{
Article \\ Risk of Liver Fibrosis According to TSH Levels in Euthyroid Subjects
}

\author{
Alba Martínez-Escudé ${ }^{1,2, *(D)}$, Guillem Pera ${ }^{1,3}$, Lluís Rodríguez ${ }^{1,4}$, Ingrid Arteaga ${ }^{1,5}$, \\ Carmen Expósito-Martínez 1,6, Pere Torán-Monserrat ${ }^{1,3}$ [1] and Llorenç Caballería ${ }^{1,3}$ (i) \\ 1 Unitat de Suport a la Recerca (USR) Metropolitana Nord, Fundació Institut Universitari d'Investigació en \\ Atenció Primària Jordi Gol i Gurina (IDIAP Jordi Gol), 08303 Mataró, Barcelona, Spain; \\ gpera@idiapjgol.info (G.P.); lrodriguezg@gencat.cat (L.R.); iarteaga@gencat.cat (I.A.); \\ cexposito.mn.ics@gencat.cat (C.E.-M.); ptoran.bnm.ics@gencat.cat (P.T.-M.); \\ lcaballeria.bnm.ics@gencat.cat (L.C.) \\ 2 Centre d'Atenció Primària La Llagosta, Institut Català de la Salut, 08120 La Llagosta, Barcelona, Spain \\ 3 Centro de Investigación Biomédica en Red de Enfermedades Hepáticas y Digestivas (CIBEREHD), \\ 28029 Madrid, Spain \\ 4 Centre d'Atenció Primària Rocafonda-Palau, Institut Català de la Salut, 08303 Mataró, Barcelona, Spain \\ 5 Centre d'Atenció Primària Santa Eulàlia, Institut Català de la Salut, \\ 08187 Santa Eulàlia de Ronçana, Barcelona, Spain \\ 6 Centre d'Atenció Primària Sabadell Centre, Institut Català de la Salut, 08201 Sabadell, Barcelona, Spain \\ * Correspondence: amescude.mn.ics@gencat.cat; Tel.: +34-93-741-5338
}

Citation: Martínez-Escudé, A.; Pera,

G.; Rodríguez, L.; Arteaga, I.;

Expósito-Martínez, C.

Torán-Monserrat, P.; Caballería, L. Risk of Liver Fibrosis According to TSH Levels in Euthyroid Subjects. J. Clin. Med. 2021, 10, 1350. https://doi.org/10.3390/jcm10071350

Academic Editor: Michael Fuchs

Received: 24 February 2021

Accepted: 22 March 2021

Published: 25 March 2021

Publisher's Note: MDPI stays neutral with regard to jurisdictional claims in published maps and institutional affiliations.

Copyright: (c) 2021 by the authors. Licensee MDPI, Basel, Switzerland. This article is an open access article distributed under the terms and conditions of the Creative Commons Attribution (CC BY) license (https:/ / creativecommons.org/licenses/by/ $4.0 /)$.
Abstract: Alterations in thyroid function may contribute to the development of liver fibrosis especially in subjects with non-alcoholic fatty liver disease. This study aimed to investigate the risk of liver fibrosis according to low-normal thyroid function in the general population. We performed a descriptive cross-sectional study in subjects from 18-75 years randomly selected from 16 primary health care centers from 2017-2019. Each subject underwent clinical evaluation, physical examination, blood analysis and transient hepatic elastography. Descriptive and multivariate logistic regression analyses were used to identify factors associated with fibrosis. We included 1096 subjects $(60 \pm 11$ years; $61 \%$ women); $70 \%$ had strict-normal thyroid function and $30 \%$ had low-normal thyroid function. Low-normal thyroid function was associated with a higher liver stiffness (LS) values: $5.2 \mathrm{vs.} 4.8 \mathrm{kPa}$ $(p=0.001)$ and a greater prevalence of fibrosis: 6.1 vs. $3 \%(p=0.016)$ and 4.3 vs. $2.1 \%(p=0.044)$ for the cut-off points of $\geq 8.0 \mathrm{kPa}$ and $\geq 9.2 \mathrm{kPa}$, respectively. After adjustment for potential confounding factors, the risk of fibrosis in subjects with low-normal thyroid function was OR $1.54(p=0.213)$. In conclusion, low-normal thyroid function is associated with higher LS values and a greater risk of liver fibrosis in the general population, being dependent on other metabolic factors.

Keywords: liver fibrosis; transient elastography; thyroid; thyroid function; thyrotropine; nonalcoholic fatty liver disease

\section{Introduction}

Liver fibrosis in subjects with chronic liver disease is a factor in bad prognosis for the development of liver cirrhosis and its consequent complications [1]. The prevalence of fibrosis in the general population ranges from 3.6 to $5.8 \%$ according to the diagnostic method used [2]. The main causes of liver fibrosis are alcohol intake, viral hepatopathies and non-alcoholic fatty liver disease (NAFLD). The latter is one of the most frequent liver diseases in our setting, affecting one fourth of the population with a prevalence that has shown to be exponentially increasing in the last years due to the rise in obesity, type 2 diabetes mellitus (T2DM) and the metabolic syndrome (MetS) [3]. At present, there are no antifibrotic treatments able to reverse or slow the progression of histological liver damage. It is essential to identify the risk factors associated with liver fibrosis in order to approach the disease from its initial or silent stages. 
It has recently been suggested that thyroid hormones may influence the development of NAFLD and the progression of liver fibrosis [4]. In some studies, hypothyroidism has been associated with NALFD independently of other factors [5], however, this relationship was not found in a recently published study including a large number of subjects [6]. On the other hand, the association between low thyroid function and liver fibrosis has also been studied, although this is still controversial [7,8]. The pathogenic mechanisms are not well defined but some common factors such as insulin resistance (IR), oxidative stress or MetS may be involved.

On the other hand, it has been suggested that low-normal thyroid function, that is, high thyroid stimulating hormone (TSH) or lower thyroxine (T4) levels within the euthyroid range, could induce similar health effects similar to those observed in hypothyroid subjects [9]. In a recent study including patients with NAFLD, low thyroid function, defined as $\mathrm{TSH} \geq 2.5 \mu \mathrm{IU} / \mathrm{mL}$, was independently associated with the presence of steatohepatitis and advanced fibrosis (F3-F4) in liver biopsy [10].

Although the association between hypothyroidism, NAFLD and liver fibrosis has been studied, there are few studies on the impact of low-normal thyroid function within the euthyroid range on the pathogenesis of fibrosis. Therefore, the aim of the present study was to investigate the risk of liver fibrosis according to low-normal thyroid function in the general population.

\section{Methods}

\subsection{Study Design and Population}

This was a descriptive, cross-sectional, multicenter population-based study. The participants included subjects from 18 to 75 years from 16 primary health care centers from the area of Barcelonès Nord and Maresme (Catalonia, Spain).

These subjects were randomly selected from the Primary Care Information System (Spanish ancronym SIAP) which is a populational database equivalent to the census in Catalonia. The exclusion criteria for the initial sample selection were: previously diagnosed chronic liver diseases, advanced severe diseases, cognitive impairment, institutionalized patients and death.

The study population was obtained from the follow-up of the populational cohort of 3014 subjects included in the recently published study by our group on the detection of liver diseases in the general population carried out from 2012 to 2016 [2]. Of the total of 3014 subjects contacted, 1684 accepted to participate in the follow-up by telephone, representing $56 \%$ of the total. Each participant underwent a clinical interview, physical examination, blood analysis and transient elastography (TE). Data were collected from January 2017 to December 2019. For the analysis we excluded subjects with incomplete laboratory data $(n=367)$, hyperthyroidism or hypothyroidism $(n=79)$, absence of or invalid elastography measurements $(n=32)$ and alcohol risk intake $(n=110)$ defined by a weekly alcohol intake $\geq 21$ standard drink units (SDU) in men and $\geq 14$ SDU in women. The final sample included was 1096 subjects.

The study protocol was approved by the IDIAP Jordi Gol Ethical Committee (P14/123) and was performed following the norms of the Declaration of Helsinki. All the subjects provided signed informed consent prior to inclusion, and the data were managed according to state legislation on data protection (LOPDGDD 3/2018).

\subsection{Clinical and Laboratory Parameters}

The following variables were collected: sociodemographic data: age and sex; anthropometric data: height, weight, waist circumference (WC) and the body mass index (BMI: weight in $\mathrm{kg}$ /height in $\mathrm{m}^{2}$ ); systolic (SBP) and diastolic blood pressure (DBP); consumption of toxic substances: tobacco and alcohol in SDU; presence of comorbidities: arterial hypertension (AHT), hypercholesterolemia, hypertriglyceridemia, overweight and obesity, T2DM, MetS and NAFLD. 
Blood analyses were performed after $12 \mathrm{~h}$ of fasting and included the determination of: complete blood count, glycemia, glycosylated hemoglobin, total cholesterol, high-density lipoproteins (HDL), low-density lipoproteins (LDL), triglycerides (TG); TSH, T4; alanine aminotransferase (ALT), aspartate aminotransferase (AST), gamma glutamyltransferase (GGT), alkaline phosphotase (ALP); total proteins and albumin.

\subsection{Definitions}

Euthyroidism was defined as TSH values between $0.35-4.94 \mu \mathrm{IU} / \mathrm{mL}$ and $\mathrm{T} 41.7-1.48 \mu \mathrm{IU} / \mathrm{mL}$, according to data from our reference laboratory. The subjects were classified into two groups for comparison: those presenting strict-normal thyroid function (TSH $\geq 0.35 \mu \mathrm{IU} / \mathrm{mL}$ and $<2.5 \mu \mathrm{IU} / \mathrm{mL}$; with normal T4 values) and those presenting lownormal thyroid function (TSH $\geq 2.5 \mu \mathrm{IU} / \mathrm{mL}$ and $\leq 4.94 \mu \mathrm{IU} / \mathrm{mL}$; with normal T4 values).

MetS was diagnosed according to the criteria of the National Cholesterol Education Program-Adult Treatment Panel III (NCEP-ATPIII) [11], when the subjects presented 3 or more of its components: WC $>88 \mathrm{~cm}$ in women and $>102 \mathrm{~cm}$ in men; TG $\geq 150 \mathrm{mg} / \mathrm{dl}$ or on hypolipemiant treatment; $\mathrm{HDL}<40 \mathrm{mg} / \mathrm{dL}$ in men and $<50 \mathrm{mg} / \mathrm{dL}$ in women or on hypolipemiant treatment; blood pressure $\geq 130 / 85 \mathrm{mmHg}$ or on hypotensive treatment; and basal glycemia $\geq 100 \mathrm{mg} / \mathrm{dL}$ or on hypolglycemia treatment.

The diagnosis of NAFLD was made using the fatty liver index (FLI) serological marker, according to $\mathrm{B} 2$ recommendations of the European guidelines [12]. The FLI includes the variables of TG, BMI, GGT and WC and is calculated based on the following formula:

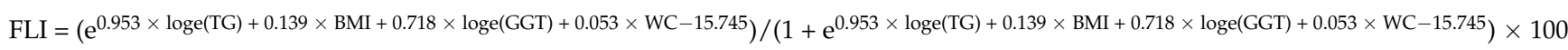

A FLI score $\geq 60$ is diagnostic of NAFLD, while a FLI score of 30-60 is indeterminate, and a score $<30$ indicates no NAFLD.

\subsection{Evaluation of Liver Fibrosis}

\subsubsection{Transient Elastography (TE)}

This was performed by a previously trained nurse using the Fibrosan 402 device (Echosens, París, France) equipped with an M probe, in all the study subjects. Subjects lacking 10 valid measurements and/or an interquartile range (IQR) of the measurement greater than $30 \%$ were excluded. Two cut-off points were established for the diagnosis of fibrosis according to the values of liver stiffness (LS) of $\geq 8.0$ kilopascals ( $\mathrm{kPa}$ ) and $\geq 9.2 \mathrm{kPa}$ (suggestive of significant liver fibrosis $\geq$ F2) [13].

\subsubsection{Serological Markers}

NAFLD fibrosis score (NFS): this score includes the variables of age, BMI, altered basal glycemia (ABG), AST, ALT, platelets and albumin and is calculated according to the following formula:

$\mathrm{NFS}=-1.675+(0.037 \times$ age $)+(0.094 \times \mathrm{BMI})+(1.13 \times \mathrm{ABG} /$ diabetes $)+(0.99 \times \mathrm{AST} / \mathrm{ALT}$ ratio $)-\left(0.013 \times\right.$ platelets $\left.\left[\times 10^{9} / \mathrm{L}\right]\right)-(0.66 \times \mathrm{albumin}[\mathrm{g} / \mathrm{dL}])$

FIB-4: includes age, AST, ALT and platelets in the formula:

$$
\text { FIB-4 }=(\text { age } \times \text { AST }) /(\text { Platelets } \times \sqrt{ }(\text { ALT }))
$$

The aspartate aminotransferase to platelet ratio index (APRI): includes AST, the upper limit of normality for AST and platelets using the formula:

$$
\text { APRI }=(\text { AST in IU } / \mathrm{L}) /\left(\text { AST upper limit of normality in U/L) } /\left(\text { Platelets in } 10^{9} / \mathrm{L}\right)\right.
$$

The criteria for predicting liver fibrosis according to the serological markers $[13,14]$ were: NFS > 0.675; FIB-4 > 3.25 and APRI > 1.5. 


\subsection{Statistical Analysis}

Continuous variables are expressed as means and standard deviation, except for those that do not have a normal distribution, which are presented as medians and IQR. Categorical variables are expressed as frequencies and percentages. The prevalences were calculated with their respective $95 \%$ confidence intervals (95\% CI).

For the comparison of variables, two groups were established based on thyroid function: strict-normal and low-normal. The chi-square test was used for categorical variables, while the Student's t test was used for continuous variables with a normal distribution and the Mann-Whitney test for variables expressed as medians.

The outcome variable was the presence of liver fibrosis defined by the LS values using two alternative cut-off points in the TE: $\geq 8.0 \mathrm{kPa}$ and $\geq 9.2 \mathrm{kPa}$. In addition, an analytical criterion was used to define liver fibrosis, which was the presence of at least one altered serological marker (NFS, FIB-4 and APRI). To evaluate whether low-normal thyroid function was independently associated with liver fibrosis, bivariate and multivariate logistic regression analyses were used adjusted for potential confounding factors. The corresponding odds ratios (OR) and their $95 \% \mathrm{CI}$ were obtained.

All the statistical tests were performed with bilateral contrasts considering statistical significance with a $p$ value $<0.05$. The analyses were carried out with the Stata version 15 package (Stata-Corp, College Station, TX, USA).

\section{Results}

\subsection{Basal Characteristics}

Of the 1096 subjets included (mean age $60 \pm 11$ years; 61\% women), 767 (70\%) were classified in the group of strict-normal thyroid function, and $329(30 \%)$ were included in the low-normal thyroid function group. Table 1 shows the basal characteristics of the study subjects. It was of note that among the participants with low-normal thyroid function, there was a greater prevalence of global obesity $(38 \% ; p=0.001)$, abdominal obesity $(57 \% ; p=0.002)$ and MetS $(34 \% ; p<0.001)$ compared to those with strict-normal thyroid function. Physical examination showed a greater BMI $(p<0.001)$ and higher WC in women with low-normal thyroid function $(p=0.005)$, as well as higher TG values (125 \pm 59 vs. $111 \pm 54 \mathrm{mg} / \mathrm{dL} ; p<0.001)$ in blood analyses.

The global prevalence of NAFLD was $37 \%(n=402)$. Differences were found in regard to the prevalence of NAFLD according to thyroid function, being $44 \%$ in subjects with low-normal thyroid function $(p=0.002)$. Hypertransaminasemia, defined as AST and/or ALT $>35 \mathrm{U} / \mathrm{L}$, affected $10 \%$ of the study subjects. The low-normal thyroid function group showed higher ALT values ( $23 \pm 16$ vs. $21 \pm 12 \mathrm{U} / \mathrm{L} ; p=0.034)$. Although the prevalence of hypertransaminasemia was greater in the low-normal thyroid function group ( $12 \%$ vs. $9.5 \%)$, these results were not significant.

\subsection{Prevalence of Fibrosis According to Thyroid Function}

Elastrography values were $\geq 8.0 \mathrm{kPa}$ and $\geq 9.2 \mathrm{kPa}$ in $3.92 \%$ and $2.7 \%$ of the subjects, respectively. Subjects with low-normal thyroid function had higher LS values compared to those with strict-normal thyroid function ( $5.2 \mathrm{vs} .4 .8 \mathrm{kPa} ; p=0.001)$. The prevalence of fibrosis was also greater in the group with low-normal thyroid function compared to the control group being $6.1 \%$ vs. $3 \%(p=0.016)$ with $\geq 8.0 \mathrm{kPa}$ and $4.3 \%$ vs. $2.1 \%(p=0.044)$ with $\geq 9.2 \mathrm{kPa}$. To the contrary, there were no statistically significant differences in the prevalence of liver fibrosis based on serological markers and thyroid function (Table 2). 
Table 1. Basal characteristics of the subjects according to thyroid function $(n=1096)$.

\begin{tabular}{|c|c|c|c|}
\hline & $\begin{array}{l}\text { Strict-Normal Thyroid } \\
\text { Function }(n=767)\end{array}$ & $\begin{array}{l}\text { Low-Normal Thyroid } \\
\text { Function }(n=329)\end{array}$ & $p$ Value \\
\hline Age (years) & $60 \pm 11$ & $61 \pm 11$ & 0.020 \\
\hline Female & $437(57 \%)$ & $229(70 \%)$ & $<0.001$ \\
\hline \multicolumn{4}{|l|}{ Toxic substances } \\
\hline Smoking Ever & $425(55 \%)$ & $159(49 \%)$ & 0.035 \\
\hline Alcohol (SDU/week) * & $0 \pm 4$ & $0 \pm 2$ & 0.001 \\
\hline \multicolumn{4}{|l|}{ Disease history } \\
\hline T2DM & $104(14 \%)$ & $55(17 \%)$ & 0.174 \\
\hline HBP & $276(36 \%)$ & $125(38 \%)$ & 0.527 \\
\hline Hypercholesterolemia & $296(39 \%)$ & $144(44 \%)$ & 0.109 \\
\hline Hypertriglyceridemia & $85(11 \%)$ & $50(15 \%)$ & 0.057 \\
\hline Global obesity & & & 0.001 \\
\hline Normal weight & $197(26 \%)$ & $75(23 \%)$ & \\
\hline Overweight $(B M I \geq 25$ to $<30)$ & $360(47 \%)$ & $128(39 \%)$ & \\
\hline Obesity $(B M \bar{I} \geq 30)$ & $210(27 \%)$ & $126(38 \%)$ & \\
\hline \multicolumn{4}{|l|}{ Abdominal obesity } \\
\hline Overall & $353(46 \%)$ & 185 (57\%) & 0.002 \\
\hline Male & $98(30 \%)$ & $36(36 \%)$ & 0.223 \\
\hline Female & $255(59 \%)$ & $149(65 \%)$ & 0.092 \\
\hline MetS & $184(24 \%)$ & $113(34 \%)$ & $<0.001$ \\
\hline FLI $\geq 60$ & $259(34 \%)$ & $143(44 \%)$ & 0.002 \\
\hline \multicolumn{4}{|l|}{ Physical examination } \\
\hline BMI & $28 \pm 4$ & $29 \pm 5$ & $<0.001$ \\
\hline WC-Male $(\mathrm{cm})$ & $98 \pm 10$ & $100 \pm 11$ & 0.106 \\
\hline WC-Female $(\mathrm{cm})$ & $91 \pm 12$ & $94 \pm 13$ & 0.005 \\
\hline $\mathrm{SBP}(\mathrm{mmHg})$ & $125 \pm 17$ & $125 \pm 17$ & 0.568 \\
\hline $\mathrm{DBP}(\mathrm{mmHg})$ & $79 \pm 10$ & $79 \pm 9$ & 0.719 \\
\hline \multicolumn{4}{|l|}{ Blood analysis } \\
\hline Glycemia (mg/dL) & $100 \pm 24$ & $101 \pm 24$ & 0.669 \\
\hline Glycosylated hemoglobin (\%) & $5.7 \pm 0.8$ & $5.7 \pm 0.7$ & 0.964 \\
\hline Total cholesterol (mg/dL) & $207 \pm 37$ & $208 \pm 39$ & 0.625 \\
\hline $\mathrm{HDL}(\mathrm{mg} / \mathrm{dL})$ & $55 \pm 13$ & $54 \pm 13$ & 0.174 \\
\hline $\mathrm{LDL}(\mathrm{mg} / \mathrm{dL})$ & $130 \pm 33$ & $130 \pm 38$ & 0.854 \\
\hline $\mathrm{TG}(\mathrm{mg} / \mathrm{dL})$ & $111 \pm 54$ & $125 \pm 59$ & $<0.001$ \\
\hline TSH $(\mu \mathrm{IU} / \mathrm{mL})$ & $1.6 \pm 0.5$ & $3.3 \pm 0.6$ & $<0.001$ \\
\hline $\mathrm{T} 4(\mu \mathrm{IU} / \mathrm{mL})$ & $0.98 \pm 0.1$ & $0.95 \pm 0.1$ & $<0.001$ \\
\hline $\operatorname{ALT}(\mathrm{U} / \mathrm{L})$ & $21 \pm 12$ & $23 \pm 16$ & 0.034 \\
\hline AST (U/L) & $22 \pm 8$ & $23 \pm 9$ & 0.220 \\
\hline $\mathrm{ALT}$ and/or AST $>35 \mathrm{U} / \mathrm{L}$ & $73(9.5 \%)$ & $40(12 \%)$ & 0.188 \\
\hline GGT $(\mathrm{U} / \mathrm{L})$ & $30 \pm 29$ & $30 \pm 35$ & 0.933 \\
\hline $\operatorname{ALP}(\mathrm{U} / \mathrm{L})$ & $79 \pm 22$ & $81 \pm 23$ & 0.284 \\
\hline Platelets $\left(10^{9} / \mathrm{L}\right)$ & $223 \pm 55$ & $228 \pm 58$ & 0.162 \\
\hline
\end{tabular}

All results are expressed in frequency (\%) or mean \pm standard deviation, except for those with * that are expressed in median \pm interquartil range. Abbr: T2DM, type 2-diabetis mellitus; HBP, high blood pressure; MetS, metabolic syndrome; FLI, fatty liver index; BMI, body max index; WC, waist circumference; SBP, systolic blood pressure; DBP, diastolic blood pressure; HDL, high density lipoprotein; LDL, low density lipoprotein; TG, triglycerides; TSH, thyroid stimulating hormone; T4, thyroxine; ALT, alanine aminotransferase; AST, aspartate aminotransferase; GGT, g-glutamyltransferase; ALP, alkaline phosphatase.

\subsection{Relationship between Thyroid Hormones and Liver Fibrosis}

On the other hand, higher TSH values were found in subjects with significant fibrosis by TE in both cut-off points for LS $8.0 \mathrm{kPa}$ and $9.2 \mathrm{kPa}$ (Table 3). There were no differences in $\mathrm{T} 4$ values. 
Table 2. Association between liver fibrosis according to thyroid function.

\begin{tabular}{cccc}
\hline & $\begin{array}{c}\text { Strict-Normal Thyroid } \\
\text { Function }(\boldsymbol{n}=\mathbf{7 6 7})\end{array}$ & $\begin{array}{c}\text { Low-Normal Thyroid } \\
\text { Function }(\boldsymbol{n}=\mathbf{3 2 9})\end{array}$ & $p$ Value \\
\hline Transient elastography & & & 0.001 \\
$\mathrm{kPa} \pm \mathrm{SD}$ & $4.8 \pm 1.6$ & $5.2 \pm 3.0$ & 0.016 \\
$\geq 8.0 \mathrm{kPa}$ & $23(3.0 \%)$ & $20(6.1 \%)$ & 0.044 \\
$\geq 9.2 \mathrm{kPa}$ & $16(2.1 \%)$ & $14(4.3 \%)$ & 0.120 \\
Serologic markers & $38(5.0 \%)$ & $24(7.4 \%)$ & 0.078 \\
NFS $>0.675$ & $8(1.1 \%)$ & $8(2.5 \%)$ & 0.031 \\
FIB4 $>3.25$ & $0(0 \%)$ & $2(0.6 \%)$ & \\
APRI $>1.5$ & & & \\
\hline
\end{tabular}

All results are expressed in frequency $(\%)$ or mean \pm standard deviation.

Table 3. Association between thyroid hormones and liver fibrosis using transient elastography.

\begin{tabular}{ccccccc}
\hline \multicolumn{7}{c}{ Transient Elastography (TE) } \\
\hline & TE $<\mathbf{8 . 0} \mathbf{~ k P a}$ & TE $\geq \mathbf{8 . 0} \mathbf{~ k P a}$ & $p$ Value & TE $<\mathbf{9 . 2} \mathbf{~ k P a}$ & TE $\geq \mathbf{9 . 2} \mathbf{~ k P a}$ & $p$ Value \\
\hline TSH $(\mu \mathrm{IU} / \mathrm{mL})$ & $2.1 \pm 1.0$ & $2.4 \pm 1.0$ & 0.015 & $2.1 \pm 1.0$ & $2.5 \pm 1.0$ & 0.034 \\
$\mathrm{~T} 4(\mu \mathrm{IU} / \mathrm{mL})$ & $0.97 \pm 0.10$ & $0.95 \pm 0.11$ & 0.130 & $0.97 \pm 0.10$ & $0.96 \pm 0.13$ & 0.546 \\
\hline
\end{tabular}

All results are expressed in mean \pm standard deviation.

The prevalence of fibrosis showed a dose-dependent increase with an increase in TSH values (Figure 1).

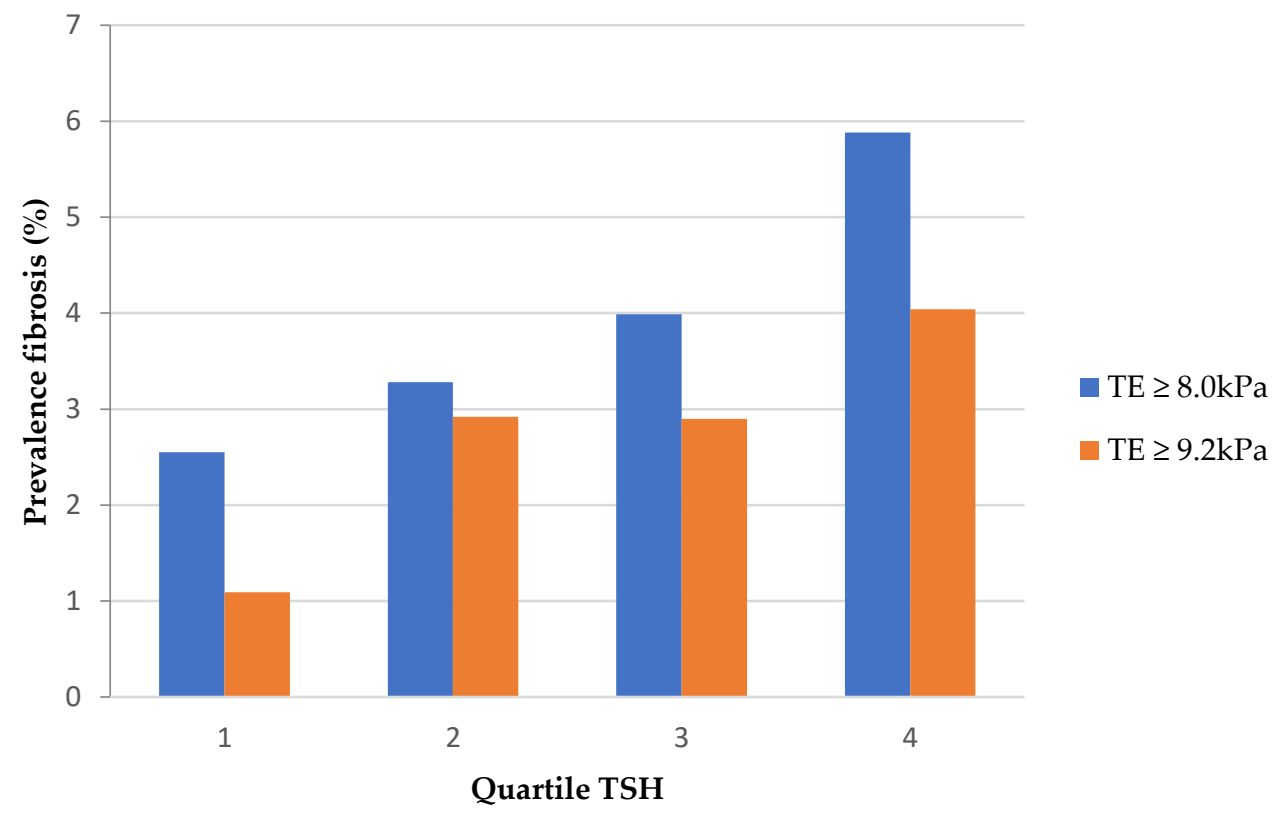

Figure 1. Prevalence of liver fibrosis according to TSH quartiles. Abbr: TE, transient elastography; $\mathrm{TSH}$, thyroid stimulating hormone.

An excess of risk of liver fibrosis of 1.44 was observed for each increase in TSH levels, independently of age, sex or alcohol intake. This excess risk was also independent of obesity and MetS for LS values $\geq 8.0 \mathrm{kPa}$ (Table 4). 
Table 4. Analysis between TSH levels ( $\mu \mathrm{IU} / \mathrm{mL}$ ) and risk of liver fibrosis, using different transient elastography cut-offs as dependent variables. Logistic regression models.

\begin{tabular}{ccc}
\hline & TE $\geq \mathbf{8 . 0} \mathbf{~ k P a}$ & TE $\geq \mathbf{9 . 2} \mathbf{~ k P a}$ \\
\hline Univariate & OR (95\%CI) $p$ value & OR (95\%CI) $p$ value \\
Multivariate * & $1.43(1.07-1.92) 0.016$ & $1.45(1.02-2.05) 0.036$ \\
Adjusted for BMI $\geq 30$ & $1.44(1.07-1.93) 0.016$ & $1.44(1.02-2.05) 0.039$ \\
Adjusted for MetS & $1.37(1.02-1.86) 0.039$ & $1.37(0.96-1.95) 0.086$ \\
Adjusted for FLI $\geq 60$ & $1.33(0.99-1.80) 0.059$ & $1.33(0.93-1.88) 0.115$ \\
& $1.28(0.95-1.74) 0.106$ & $1.26(0.88-1.81) 0.201$
\end{tabular}

* All multivariate analyses are adjusted also for age, sex and alcohol intake. Correlation between TSH levels and $\mathrm{TE}(\mathrm{kPa}) \mathrm{r}=0.07$. Abbr: BMI, body max index; MetS, metabolic syndrome; FLI, fatty liver index; TE, transient elastrography; $\mathrm{OR}$, odds ratio; $\mathrm{CI}$, confidence interval; $\mathrm{TSH}$, thyroid stimulating hormone.

\subsection{Risk of Fibrosis According to Thyroid Function}

The univariate analysis detected an increase in the risk of fibrosis in subjects with low-normal thyroid function which was 2.09 -fold greater for both LS values $\geq 8.0 \mathrm{kPa}$ and $\geq 9.2 \mathrm{kPa}$ (Table 5).

Table 5. Analysis of risk of liver fibrosis using different transient elastography cut-offs as dependent variables, in low-normal thyroid function (TSH 2.5-4.94 $\mu \mathrm{IU} / \mathrm{mL}$ ) vs. strict-normal thyroid function $(\mathrm{TSH}<2.5 \mu \mathrm{IU} / \mathrm{mL})$. Logistic regression models.

\begin{tabular}{ccc}
\hline & TE $\geq \mathbf{8 . 0} \mathbf{~ k P a}$ & TE $\geq \mathbf{9 . 2} \mathbf{~ k P a}$ \\
\hline Univariate & OR (95\%CI) $p$ value & OR (95\%CI) $p$ value \\
Multivariate * & $2.09(1.13-3.87) 0.018$ & $2.09(1.01-4.33) 0.048$ \\
& $2.11(1.13-3.95) 0.019$ & $2.08(0.99-4.36) 0.053$ \\
\hline
\end{tabular}

* Also adjusted for age, sex and alcohol intake. Abbr: TE, transient elastography; OR, odds ratio; CI, confidence interval; TSH, thyroid stimulating hormone.

Multivariate analysis adjusted for age, sex and alcohol intake showed a significant association between low-normal thyroid function and elastrography values of $\geq 8.0 \mathrm{kPa}$ (OR 2.11) and $\geq 9.2 \mathrm{kPa}$ (OR 2.08). To evaluate whether the association between lownormal thyroid function and fibrosis by elastography was independent of other factors, multivariate analyses were performed using separate models, adjusted for obesity, MetS and NAFLD. We observed no independent or significant increase in the risk of fibrosis in subjects with low-normal thyroid function for the two elastography cut-off points used in relation to the presence of obesity, MetS or NAFLD (Table 6).

Table 6. Multivariate analysis of risk of liver fibrosis using different transient elastography cut-offs as dependent variables in low-normal thyroid function (TSH 2.5-4.94 $\mu \mathrm{IU} / \mathrm{mL}$ ) vs. strict-normal thyroid function (TSH $<2.5 \mu \mathrm{IU} / \mathrm{mL}$ ). Three different multivariate logistic regression models adjusted for BMI, MetS and FLI.

\begin{tabular}{ccc}
\hline & TE $\geq \mathbf{8 . 0} \mathbf{~ k P a}$ & TE $\geq \mathbf{9 . 2} \mathbf{k P a}$ \\
\hline TSH $2.5-4.94(\mu \mathrm{IU} / \mathrm{mL}) *$ & OR $(95 \% \mathrm{CI}) p$ value & OR $(95 \% \mathrm{CI}) p$ value \\
$\mathrm{BMI} \geq 30$ & $1.78(0.94-3.36) 0.077$ & $1.68(0.79-3.56) 0.180$ \\
$\mathrm{TSH} 2.5-4.94(\mu \mathrm{IU} / \mathrm{mL}) *$ & $6.63(3.27-13.46)<0.001$ & $11.31(4.25-30.06)<0.001$ \\
MetS & $1.78(0.94-3.37) 0.075$ & $1.71(0.80-3.64) 0.163$ \\
$\mathrm{TSH} 2.5-4.94(\mu \mathrm{IU} / \mathrm{mL}) *$ & $5.58(2.81-11.08)<0.001$ & $7.35(3.12-17.34)<0.001$ \\
FLI $\geq 60$ & $1.66(0.87-3.16) 0.123$ & $1.58(0.73-3.38) 0.244$ \\
\hline
\end{tabular}

* All multivariate analyses are also adjusted for age, sex and alcohol intake. Each model shows the OR for TSH (in bold) and the specific adjusted variable (BMI, MetS, FLI) ORs. No interaction between low-normal thyroid function, obesity, MetS and NAFLD in the statistical analysis ( $p$ value $\geq 0.2$ ). Abbr: BMI, body max index; MetS, metabolic syndrome; FLI, fatty liver index; TSH, thyroid stimulating hormone; $\mathrm{TE}$, transient elastrography. 
On the other hand, in an analysis adjusted for the specific components of MetS (Table 7), both WC and glycemia were significantly associated with fibrosis with the LS values $\geq 8.0 \mathrm{kPa}$ and $\geq 9.2 \mathrm{kPa}$. TG were related to LS values $\geq 9.2 \mathrm{kPa}$ and HDL with LS $\geq 8.0 \mathrm{kPa}$, while $\mathrm{BP}$ was not associated with liver fibrosis. To the contrary, low-normal thyroid function was not found to be an independent factor of the MetS components for fibrosis with LS values $\geq 8.0 \mathrm{kPa}(\mathrm{OR} 1.54 ; p=0.213)$ and $\geq 9.2 \mathrm{kPa}(\mathrm{OR} 1.42 ; p=0.391)$.

Table 7. Multivariate analysis of risk of liver fibrosis using different transient elastography cut-offs as dependent variables in low-normal thyroid function (TSH 2.5-4.94 $\mu \mathrm{IU} / \mathrm{mL}$ ) vs. strict-normal thyroid function (TSH $<2.5 \mu \mathrm{IU} / \mathrm{mL}$ ). Multivariate logistic regression models adjusted for all the different parameters of MetS.

\begin{tabular}{ccc}
\hline & TE $\geq \mathbf{8 . 0} \mathbf{~ k P a}$ & TE $\geq \mathbf{9 . 2} \mathbf{~ k P a}$ \\
\hline $\mathrm{TSH} 2.5-4.94(\mu \mathrm{IU} / \mathrm{mL})^{*}$ & OR $(95 \% \mathrm{CI}) p$ value & OR (95\%CI) $p$ value \\
$\mathrm{WC}>88 />102 \mathrm{~cm} \mathrm{female} / \mathrm{male}$ & $1.54(0.78-3.02) 0.213$ & $1.42(0.64-3.13) 0.391$ \\
$\mathrm{TG} \geq 150 \mathrm{mg} / \mathrm{dL}$ & $6.90(2.53-18.78)<0.001$ & $2.33(2.08-25.86) 0.002$ \\
$\mathrm{HDL}<50 / 40 \mathrm{mg} / \mathrm{dL} \mathrm{female} / \mathrm{male}$ & $1.99(0.97-4.08) 0.060$ & $2.27(0.95-5.40) 0.028$ \\
$\mathrm{BP} \geq 130 / 85 \mathrm{mmHg}$ & $2.30(1.11-4.76) 0.025$ & $0.69(0.31-1.52) 0.355$ \\
Glucose $\geq 100 \mathrm{mg} / \mathrm{dL}$ & $0.57(0.29-1.13) 0.110$ & $3.38(1.30-8.79) 0.013$ \\
\hline
\end{tabular}

* Also adjusted for age, sex and alcohol intake. All variables mutually adjusted. Abbr: WC, waist circumference; TG, trygliceride; HDL high-density lipoprotein; BP, blood pressure; TSH, thyroid stimulating hormone; TE, transient elastrography.

Finally, neither was any association found between low-normal thyroid function and the risk of fibrosis using the serological markers analyzed in the multivariate analysis adjusted for age, sex, alcohol intake and the different parameters of MetS (OR 0.84; 95\%CI $0.63-1.13 ; p=0.244)$.

\section{Discussion}

The findings of the present study demonstrate that low-normal thyroid function is associated with a two-fold greater risk of liver fibrosis compared to strict-normal thyroid function. To our knowledge, this is the first European study to evalulate the risk of liver fibrosis in the general population according to thyroid function within the euthyroid range. Although these results are clinically relevant, the increase in the risk found was not independent of parameters of the MetS or the other factors studied.

It is well known that thyroid hormones participate in multiple processes of metabolism, such as lipolysis, neoglucogenesis as well as the regulation of weight and temperature. The effects of low thyroid function on health, specifically hypothyroidism, include a greater prevalence of obesity, dyslipemia, MetS and greater IR, which are determinant factors for the development of NAFLD [15-17]. At a hepatic level, thyroid hormones are involved in beta oxidation of the fatty acids and could influence the accumulation of fat in the liver. The main thyroid hormone receptor (THR) expressed in the liver is THR $\beta$ and its role was demonstrated in a study designed with mice, where a dominant negative mutation in THR $\beta$ was analyzed and it was observed that these mice developed hepatic steatosis in a few months [18]. Other physiopathological mechanisms involved in NAFLD/NASH such as the role of adipocytokines, oxidative stress reactions, mitochondrial dysfunction or lipid peroxidation have also been related to thyroid hormones [19]. The activation of hepatic stellate cells is an important step in liver fibrogenesis [20]. In case of liver injury, it has been suggested that inhibition of nuclear THR expression may activate hepatic stellate cells favoring the fibrogenic response [19,21].

Some studies have demonstrated results similar to those of our study, although few studies have evaluated the effect of low-normal thyroid function within the euthyroid range on liver fibrosis. Kim et al. [10] demonstrated that subjects with NAFLD and low thyroid function, defined as TSH $\geq 2.5 \mu \mathrm{IU} / \mathrm{mL}$, have a greater risk of developing non-alcoholic steatohepatitis (NASH) and advanced fibrosis (stages F3-F4 in liver biopsy). Another study carried out in the general population, including 7259 participants, found an increase 
in the risk of advanced fibrosis defined by serological markers, which was 2-fold higher in subjects with low-normal thyroid function with respect to a group with strict-normal function independently of the WC, cholesterol values or IR [22]. To the contrary, in our study there was no association between low-normal thyroid function and an alteration in serological markers of fibrosis.

The effects of thyroid hormones on liver fibrosis have also been studied. Specifically, TSH levels have been associated with LS values $\geq 8.0 \mathrm{kPa}$ in patients with NAFLD diagnosed by FLI [23]. We also found an increase in TSH values in euthyroid subjects with liver fibrosis as well as an excess of risk of LS $\geq 8.0 \mathrm{kPa}$, of 1.44 for each increase in TSH unit independently of the presence of obesity or MetS. On the other hand, Manka et al. found an association between low T3 levels and liver fibrosis (by TE or serological markers) but could not demonstrate the relationship between TSH and T4 levels with LS in subjects with NASH [8].

One aspect of note in the present study, which excluded the main causes of chronic liver disease including alcohol risk intake, was that the prevalence of fibrosis found might be attributed to NAFLD in most of the cases. In fact, the prevalence of NAFLD in subjects with low-normal thyroid function was significantly greater, affecting almost half of these individuals.

Other authors have studied the role of thyroid hormones within the reference range in NAFLD. Low T4 levels have been associated with the risk of NAFLD in euthyroid subjects [24], and in some studies this association was independent of the presence of MetS [25]. On the other hand, high TSH levels have been related to NAFLD [26,27]. In a recent meta-analysis including 61,548 subjects, there was a significant increase in TSH values in subjects with NAFLD compared to a control group, with a weighted mean difference of 0.105 (95\%CI 0.012-0.197), concluding that this could be a risk factor for the development and progression of NAFLD [28]. In contrast, this association has not been demonstrated in other studies [29].

According to the data available, low-normal thyroid function has been related to moderate increases in total cholesterol, LDL and TG values [30]. Likewise, it has been linked to greater IR and an increase in the risk of MetS similar to what occurs in patients with hypothyroidism [31,32]. Elevated TSH levels, even within the reference range, have also been related to an increase in central obesity, among other alterations such as hyperglycemia, hyperuricemia, elevation in blood pressure, hypercoagulability or an increase in inflammatory markers [33]. Thus, our study shows similar results with increases in the prevalence of obesity and MetS and elevations in TG levels in subjects with low-normal thyroid function. These findings are clinically important, since these factors may not only have implications in the cardiovascular system but may exacerbate the development of NAFLD and liver fibrosis given the common physiopathogenic mechanisms. In fact, in a study with a mean follow-up of 23 years, the univariate model demonstrated that low thyroid function (including low-normal euthyroidism and hypothyroidism) was associated with a greater risk of mortality in subjects with NAFLD [34]. Taking all of this into account, some authors have suggested that the reference range of normality for thyroid function should be reevaluated.

The present study has some limitations. The cross-sectional design did not allow the determination of a relation of causality among the variations of thyroid function and liver fibrosis. The gold standard method for determining the grade of fibrosis is liver biopsy [35], but since this is an invasive test it cannot be routinely performed. In our case, we used validated serological markers and measurements of LS by TE, which has a sensitivity of 95-98\% [36]. The XL probe is recommended for measuring LS in subjects with obesity, but in our study all the TE were performed with the M probe because it was the only probe available. Finally, thyroid hormones values may have undergone temporal modifications and the impact of this on the liver is unknown. 


\section{Conclusions}

In conclusion, the findings of this study demonstrate that low-normal thyroid function is associated with a greater risk of liver fibrosis in the general population, although dependently of other metabolic factors. These data demonstrate the need to reconsider the objectives of thyroid hormones control in patients with risk factors for the development of liver fibrosis.

Author Contributions: Conceptualization, A.M.-E., P.T.-M. and L.C.; Methodology, A.M.-E., G.P. and L.C.; Validation, A.M.-E., G.P., P.T.-M. and L.C.; Investigation, A.M.-E., L.R., I.A. and C.E.-M.; Supervision, A.M.-E., L.R., I.A. and C.E.-M.; Formal analysis and data curation, G.P.; Writing-Original Draft Preparation, A.M.-E.; Writing-Review \& Editing, A.M.-E. and L.C.; Funding Acquisition, L.C. All authors have read and agreed to the published version of the manuscript.

Funding: This study is part of the project "Valor predictivo de la elastografía hepática transitoria respecto a la enfermedad hepática y cardiovascular" and obtained funding from the Carlos III Institute of Health, Ministry of Economy and Competitiveness (Spain), in the FIS with reference PI14/00407 (PI Llorenç Caballería Rovira). Alba Martínez-Escudé received a grant of researcher furtherment from IDIAP Jordi Gol 2020.

Institutional Review Board Statement: The study was conducted according to the guidelines of the Declaration of Helsinki, and approved by the Ethics Committee of IDIAP Jordi Gol Institute (P14/123).

Informed Consent Statement: Informed consent was obtained from all subjects involved in the study.

Data Availability Statement: Data sharing not applicable.

Acknowledgments: The authors thank Anna Costa for her support of this project.

Conflicts of Interest: The authors declare no conflict of interests.

\section{References}

1. Angulo, P.; Kleiner, D.E.; Dam-Larsen, S.; Adams, L.A.; Björnsson, E.S.; Charatcharoenwitthaya, P.; Mills, P.R.; Keach, J.C.; Lafferty, H.D.; Stahler, A.; et al. Liver Fibrosis, but No Other Histologic Features, Is Associated With Long-term Outcomes of Patients With Nonalcoholic Fatty Liver Disease. Gastroenterology 2015, 149, 389-397.e10. [CrossRef]

2. Caballería, L.; Pera, G.; Arteaga, I.; Rodríguez, L.; Alumà, A.; Morillas, R.M.; de la Ossa, N.; Díaz, A.; Expósito, C.; Miranda, D.; et al. High Prevalence of Liver Fibrosis Among European Adults With Unknown Liver Disease: A Population-Based Study. Clin. Gastroenterol. Hepatol. 2018, 16, 1138-1145.e5. [CrossRef] [PubMed]

3. Younossi, Z.; Anstee, Q.M.; Marietti, M.; Hardy, T.; Henry, L.; Eslam, M.; George, J.; Bugianesi, E. Global burden of NAFLD and NASH: Trends, predictions, risk factors and prevention. Nat. Rev. Gastroenterol. Hepatol. 2018, 15, 11-20. [CrossRef] [PubMed]

4. He, W.; An, X.; Li, L.; Shao, X.; Li, Q.; Yao, Q.; Zhang, J.-A. Relationship between Hypothyroidism and Non-Alcoholic Fatty Liver Disease: A Systematic Review and Meta-analysis. Front. Endocrinol. 2017, 8, 335. [CrossRef] [PubMed]

5. Chung, G.E.; Kim, D.; Kim, W.; Yim, J.Y.; Park, M.J.; Kim, Y.J.; Yoon, J.-H.; Lee, H.-S. Non-alcoholic fatty liver disease across the spectrum of hypothyroidism. J. Hepatol. 2012, 57, 150-156. [CrossRef] [PubMed]

6. Martínez Escudé, A.; Pera, G.; Arteaga, I.; Expósito, C.; Rodríguez, L.; Torán, P.; Caballeria, L. Relación entre el hipotiroidismo y el hígado graso no alcohólico en una población española. Med. Clínica 2020, 154, 1-6. [CrossRef] [PubMed]

7. Bano, A.; Chaker, L.; Muka, T.; Mattace-Raso, F.U.S.; Bally, L.; Franco, O.H.; Peeters, R.P.; Razvi, S. Thyroid Function and the Risk of Fibrosis of the Liver, Heart, and Lung in Humans: A Systematic Review and Meta-Analysis. Thyroid 2020, 30, 806-820. [CrossRef]

8. Manka, P.; Bechmann, L.; Best, J.; Sydor, S.; Claridge, L.C.; Coombes, J.D.; Canbay, A.; Moeller, L.; Gerken, G.; Wedemeyer, H.; et al. Low Free Triiodothyronine Is Associated with Advanced Fibrosis in Patients at High Risk for Nonalcoholic Steatohepatitis. Dig. Dis. Sci. 2019, 64, 2351-2358. [CrossRef]

9. Van Tienhoven-Wind, L.J.N.; Dullaart, R.P.F. Low-normal thyroid function and the pathogenesis of common cardio-metabolic disorders. Eur. J. Clin. Investig. 2015, 45, 494-503. [CrossRef]

10. Kim, D.; Kim, W.; Joo, S.K.; Bae, J.M.; Kim, J.H.; Ahmed, A. Subclinical Hypothyroidism and Low-Normal Thyroid Function Are Associated With Nonalcoholic Steatohepatitis and Fibrosis. Clin. Gastroenterol. Hepatol. 2018, 16, 123-131.e1. [CrossRef]

11. National Cholesterol Education Program (NCEP) Expert Panel on Detection, Evaluation, and Treatment of High Blood Cholesterol in Adults (Adult Treatment Panel III). Third Report of the National Cholesterol Education Program (NCEP) Expert Panel on Detection, Evaluation, and Treatment of High Blood Cholesterol in Adults (Adult Treatment Panel III) final report. Circulation 2002, 106, 3143-3421. [CrossRef] 
12. European Association for the Study of the Liver (EASL); European Association for the Study of Diabetes (EASD). European Association for the Study of Obesity (EASO) EASL-EASD-EASO Clinical Practice Guidelines for the management of non-alcoholic fatty liver disease. J. Hepatol. 2016, 64, 1388-1402. [CrossRef]

13. Castera, L.; Friedrich-Rust, M.; Loomba, R. Noninvasive Assessment of Liver Disease in Patients with Nonalcoholic Fatty Liver Disease. Gastroenterology 2019, 156, 1264-1281.e4. [CrossRef] [PubMed]

14. Younossi, Z.M.; Loomba, R.; Anstee, Q.M.; Rinella, M.E.; Bugianesi, E.; Marchesini, G. Diagnostic modalities for nonal-coholic fatty liver disease, nonalcoholic steatohepatitis, and associated fibrosis. Hepatology 2018, 68, 349-360. [CrossRef] [PubMed]

15. Ferrandino, G.; Kaspari, R.R.; Spadaro, O.; Reyna-Neyra, A.; Perry, R.J.; Cardone, R.; Kibbey, R.G.; Shulman, G.I.; Dixit, V.D.; Carrasco, N. Pathogenesis of hypothyroidism-induced NAFLD is driven by intra- and extrahepatic mechanisms. Proc. Natl. Acad. Sci. USA 2017, 114, E9172-E9180. [CrossRef]

16. Yang, L.; Lv, X.; Yue, F.; Wei, D.; Liu, W.; Zhang, T. Subclinical hypothyroidism and the risk of metabolic syndrome: A metaanalysis of observational studies. Endocr. Res. 2016, 41, 158-165. [CrossRef]

17. Iwen, K.A.; Schröder, E.; Brabant, G. Thyroid Hormones and the Metabolic Syndrome. Eur. Thyroid. J. 2013, 2, 83-92. [CrossRef]

18. Araki, O.; Ying, H.; Zhu, X.G.; Willingham, M.C.; Cheng, S.Y. Distinct Dysregulation of Lipid Metabolism by Unliganded Thyroid Hormone Receptor Isoforms. Mol. Endocrinol. 2009, 23, 308-315. [CrossRef] [PubMed]

19. Gionfra, F.; De Vito, P.; Pallottini, V.; Lin, H.-Y.; Davis, P.J.; Pedersen, J.Z.; Incerpi, S. The Role of Thyroid Hormones in Hepatocyte Proliferation and Liver Cancer. Front. Endocrinol. 2019, 10, 532. [CrossRef] [PubMed]

20. Higashi, T.; Friedman, S.L.; Hoshida, Y. Hepatic stellate cells as key target in liver fibrosis. Adv. Drug Deliv. Rev. 2017, 121, 27-42. [CrossRef]

21. Manka, P.; Coombes, J.; Bechmann, L.; Dollé, L.; Swiderska-Syn, M.; Briones-Orta, M.; Williams, R.; Van Grunsven, L.; Canbay, A.; Flamant, F; et al. Thyroid Hormone receptor regulates hepatic stellate cell activation. J. Hepatol. 2017, 66, S582. [CrossRef]

22. Kim, D.; Yoo, E.R.; Li, A.A.; Fernandes, C.T.; Tighe, S.P.; Cholankeril, G.; Hameed, B.; Ahmed, A. Low-Normal Thyroid Function Is Associated With Advanced Fibrosis Among Adults in the United States. Clin. Gastroenterol. Hepatol. 2019, 17, $2379-2381$. [CrossRef]

23. Bano, A.; Chaker, L.; Plompen, E.P.C.; Hofman, A.; Dehghan, A.; Franco, O.H.; Janssen, H.L.A.; Murad, S.D.; Peeters, R.P. Thyroid Function and the Risk of Nonalcoholic Fatty Liver Disease: The Rotterdam Study. J. Clin. Endocrinol. Metab. 2016, 101, 3204-3211. [CrossRef]

24. Xu, C.; Xu, L.; Yu, C.; Miao, M.; Li, Y. Association between thyroid function and nonalcoholic fatty liver disease in euthyroid elderly Chinese. Clin. Endocrinol. 2011, 75, 240-246. [CrossRef]

25. Berg, E.H.V.D.; van Tienhoven-Wind, L.J.; Amini, M.; Schreuder, T.C.; Faber, K.N.; Blokzijl, H.; Dullaart, R.P. Higher free triiodothyronine is associated with non-alcoholic fatty liver disease in euthyroid subjects: The Lifelines Cohort Study. Metabolism 2017, 67, 62-71. [CrossRef]

26. Liu, Y.; Wang, W.; Yu, X.; Qi, X. Thyroid Function and Risk of Non-Alcoholic Fatty Liver Disease in Euthyroid Subjects. Ann. Hepatol. 2018, 17, 779-788. [CrossRef]

27. Zhang, X.; Zhang, J.; Dai, Y.; Qin, J. Serum Thyroid Hormones Levels are Significantly Associated with Nonalcoholic Fatty Liver Disease in Euthyroid Chinese Population. Clin. Lab. 2020, 66, 66. [CrossRef] [PubMed]

28. Guo, Z.; Li, M.; Han, B.; Qi, X. Association of non-alcoholic fatty liver disease with thyroid function: A systematic review and meta-analysis. Dig. Liver Dis. 2018, 50, 1153-1162. [CrossRef] [PubMed]

29. Jaruvongvanich, V.; Sanguankeo, A.; Upala, S. Nonalcoholic Fatty Liver Disease Is Not Associated with Thyroid Hormone Levels and Hypothyroidism: A Systematic Review and Meta-Analysis. Eur. Thyroid. J. 2017, 6, 208-215. [CrossRef] [PubMed]

30. Van Tienhoven-Wind, L.J.N.; Dullaart, R.P.F. Low-Normal Thyroid Function and Novel Cardiometabolic Biomarkers. Nutrients 2015, 7, 1352-1377. [CrossRef] [PubMed]

31. Roos, A.; Bakker, S.J.L.; Links, T.P.; Gans, R.O.B.; Wolffenbuttel, B.H.R. Thyroid Function Is Associated with Components of the Metabolic Syndrome in Euthyroid Subjects. J. Clin. Endocrinol. Metab. 2006, 92, 491-496. [CrossRef] [PubMed]

32. Kim, B.-J.; Kim, T.Y.; Koh, J.-M.; Kim, H.-K.; Park, J.-Y.; Lee, K.-U.; Shong, Y.K.; Kim, W.B. Relationship between serum free T4 (FT4) levels and metabolic syndrome (MS) and its components in healthy euthyroid subjects. Clin. Endocrinol. 2009, 70, 152-160. [CrossRef] [PubMed]

33. Chang, Y.-C.; Hua, S.-C.; Chang, C.-H.; Kao, W.-Y.; Lee, H.-L.; Chuang, L.-M.; Huang, Y.-T.; Lai, M.-S. High TSH Level within Normal Range Is Associated with Obesity, Dyslipidemia, Hypertension, Inflammation, Hypercoagulability, and the Metabolic Syndrome: A Novel Cardiometabolic Marker. J. Clin. Med. 2019, 8, 817. [CrossRef] [PubMed]

34. Kim, D.; Vazquez-Montesino, L.M.; Escober, J.A.; Fernandes, C.T.; Cholankeril, G.; Loomba, R.; Harrison, S.A.; Younossi, Z.M.; Ahmed, A. Low Thyroid Function in Nonalcoholic Fatty Liver Disease Is an Independent Predictor of All-Cause and Cardiovascular Mortality. Am. J. Gastroenterol. 2020, 115, 1496-1504. [CrossRef]

35. Chalasani, N.; Younossi, Z.; LaVine, J.E.; Diehl, A.M.; Brunt, E.M.; Cusi, K.; Sanyal, A.J. The diagnosis and management of non-alcoholic fatty liver disease: Practice Guideline by the American Association for the Study of Liver Diseases, American College of Gastroenterology, and the American Gastroenterological Association. Hepatology 2012, 55, 2005-2023. [CrossRef]

36. Caballeria, L.; Augustin, S.; Broquetas, T.; Morillas, R.M.; Vergara, M.; Virolés, S.; Hernández, M.R.; Serra, I.; Goday, A.; Vila, L.; et al. Recomendaciones para la detección, diagnóstico y seguimiento de los pacientes con enfermedad por hígado graso no alcohólico en atención primaria y hospitalaria. Med. Clínica 2019, 153, 169-177. [CrossRef] [PubMed] 